\title{
Depiction of Violent Crimes in Bollywood Cinema and its Impact on Pakistani Society
}

\section{Erum Hafeez*}

\begin{abstract}
This study aims at examining the possible relationship between increasing violence in Pakistani society and its excessive portrayal in popular Indian movies, ardently watched in Pakistan, during 1970s, 80s, 90s and 2000s. Firstly, five top grossing films selected through popularity charts and youth polls are analyzed from the four decades under study. Then Violence Index, as per adjusted George Gerbner's Formula, 1976, is calculated to identify and compare the trends in the defined time period. Subsequently, four samples of one month issues of the largest circulated Daily Jang from each decade (1976-2006) were carefully analyzed for crime news as an authentic daily record of social crime scene in the country. Results show that violence has increased both in Pakistani society and Indian movies during the forty years sampled but the increase is curvilinear rather than linear in nature. Only a negligibly weak correlation of +0.2 is being found between the incidences of silver screen violence and real-life, reported crimes. Though, there seems to be fragile relationship between the two variables, it is observed that the violent crimes rate in Pakistani society fluctuate, following the trends and frequency of portrayal of violence in Indian movies in preceding decade under study.
\end{abstract}

Key Words: Bollywood, Cinema, Violent Crimes, Pakistani Society, Real-life, Reel-life. Effect Studies

*Associate Professor, Institute of Business Management (Iobm), Karachi, Pakistan 
Jhss, Vol. 8, No. 1 , January to June, 2017

\section{Introduction and Background:}

The society in Indo-Pak subcontinent is believed to be under the immense influence of large and empathic Indian film industry. The Press Trust of India claimed that India has the largest film industry in the world popularly known as Bollywood and often referred to as Hindi Cinema. Its annual worldwide ticket sales are worth $\$ 3.5$ billion. Bollywood churns out approximately 8001000 movies every year. ${ }^{1}$ Indian Cinema is recognized globally and has a large viewership in almost every region of the world. Due to its international appeal, Bollywood movies are exported to over hundred countries across the world. These movies generate around 30\% of their potential profit from overseas markets.

It is further assumed that satellite television and fast growing home video segment of cable TV are new alternative distribution means that expectedly expand the Bollywood films market. Considering the popularity of Indian movies in Pakistan and its easy accessibility to local mass viewers through satellite television, home video cable channels, videocassette, DVDs and later countrywide display in native cinema halls, one can assume that it plays an important role in developing the concepts of life by transmitting patterns of conduct and sharing popular culture.

Violence and Crimes are the hot cakes that have always attracted filmmakers world over due to its mass appeal. For people of all ages greatest exposure to violence comes from movies. Researchers have identified that Love, Crime and Sex are the ever green themes that have dominated $75 \%$ of the commercial films, produced world over since the arrival of film in the late 19 th century. It is crucial to note that depiction of violence in films is often unrealistic and exaggerated. Fighting and killings are often projected as a practical and easy solution in crisis without any hint to its consequences especially when it involved heroes versus villains.

It has raised frequent concerns about the potentially damaging effects of these silver screen images on the vulnerable sections of society. In about three thousand studies which are conducted over the last five decades, researchers have argued that incessant and excessive exposure to on-screen

1 APF Reporter 21 \# index. (2010). Gateway's of India Globalization. Retrieved from aliciapatterson.org: http://aliciapatterson.org/APF2101/Wells/Wells.html 
violence often leads to anti-social and aggressive behaviour when complemented with hostile surroundings at home and in the wider society.

The impact on behaviour is evident. However, it is not that simple to blame onscreen violence for rising crime rate in society due to various reasons. Essentially, very few criminals and deviants are found guilty because of their heavy exposure to onscreen violence. On the contrary, a large majority of the viewer's seem to be unaffected. Though most researches fail to find a straight cause-and-effect link between real and reel world violence, they do recognize multiple, indirect circumstantial links.

The current research examines the possible correlation between increasing violence in Pakistani society and its excessive portrayal in popular Bollywood films that are equally popular in the country.

\section{Literature Review:}

The present study heavily relies on the theories and studies of culture and learning which analyses the relationship between on-screen violence and vulnerable viewers who might be tempted to replicate media violence in real life.

Bandura through his social learning theory established that most people, especially children, learn and adopt behavior following striking role models both in the real world and in media. ${ }^{2}$ Jarvie has also pointed out that film often contributes to social reality but in an extremely slow and subtle manner. ${ }^{3}$

It would appear to be the case that changes in attitude and behaviour express themselves only occasionally and in a seemingly erratic manner, which appears to be the case in our own correlation of crime rates in films and in the world beyond the cinema. This study also hypothesizes that people learn and adopt deviant and even criminal behaviors as a ready reaction and quick solution to social injustice when they observe positive reinforcement of deviant actions in media. Even if the majority of viewers does not turn criminal in reaction to exposure to violent films, they may become desensitized or fearful if they take on-screen violence to be a true representation of the age.

2 Albert Bandura, Social Foundations of Thoughts and Actions: a Social Cognitive Theory, Englewood Cliffs, NJ: Prentice-Hall, 1986, pp. 47-80

3 Ian Jarvie, Movies and Society, New York: Basic Books, 1970, pp. 24-25 
In Asia, some significant research studies have been found related to the impact of local and international media especially Film and TV on Asian viewers such as a content analysis in Malaysia conducted in early eighties that harshly condemned the increasing rate of violence in cartoons, films and other programs on Malaysian TV channels.

It is evidently indicated that media violence is no more a western concern only as several researchers signify swift global reach of media content that uniformly target Asian and Indian viewers especially youth with equally graphic programs and resulted into identical "problems of imitation, desensitization, fear, and inappropriate attitudes" towards real life violence both in the East as well as the West. ${ }^{4}$

More specifically in Indo-Pak region, a few researches on Indian movies and some articles were found that highlighted the historical evolution of Indian film industry and its impact on the society. Art and life have fused in Indian society. Cinema depicts popular political philosophies, social values, group behaviour, folk language $\&$ fashion in India and like a mirror, reflects back in society. The understanding of the phenomenon will facilitate to examine India's self-perception and Bollywood' contribution in fostering India's image as a bog brother and regional power in South Asia. ${ }^{5}$

Kiran Shaheen investigated Portrayal of Police Torture in Hindi Films and Television Serials and its psychological impact on Children in India .The study was planned to understand how torture and other forms of violence replicated in popular electronic media and how the media consequently manipulate viewers particularly children. According to the results, around 178 acts of violence were counted in one form or the other in a single day televised programs across the channel offered in India which is often blatant and brutal in its treatment. The study revealed that the children from poor class spent more time watching television and films than the kids from upper and middle classes. Moreover the same class children were more afraid of such torture scenes since they often exposed to such situations in their dayto-day lives. Boys especially from lower income group were found to be fonder of police torture and police characters than their female counterparts. While it is rather middle and upper income group kids who drew pleasure

4 Strasburger, V. C. (1999). Media Violence. Behavioural Pediatrics-II. 66, 603-612. Indian J Pediatr.

5 Ahmed, A. S. (1992). Bombay Films: The Cinema as Metaphor for Indian Society and Politics. Modern Asian Studies, 26 (2), 289-320. 
from the scenes where police torture the villain may be because of their protected position in the society. ${ }^{6}$

Ramasubramanian and Oliver conducted an exploratory content analysis to observe portrayals of gender-based violence in popular Hindi films in 2000. Nine films were arbitrarily chosen from box office hits between 1997 and 1999. It was found that women were mostly portrayed as victims than men. Heroes were more likely to be involved in moderate violence such as sexual harassment especially targeting the female lead that ultimately leads to infatuation and then filmi romance. While intense sexual violence was condemned as criminal and serious, moderate sexual violence was often glamourized as fun and adoring in Indian films. ${ }^{7}$

There is another report about nine Asian countries which discovered that Asian children mostly prefer adult programs than locally produced children programs especially foreign films and cartoons. It revealed that merely three out of seven countries that include China, Vietnam and Japan have favourable policies for the production of quality children's programs while most countries are completely ignorant of UN Charter on Children's Rights and hardly offer specialized programs for preteens and teens. ${ }^{8}$

\section{Methodology and Sampling}

To gauge the changes in frequency and depiction of violence and crimes both on and off screen during the targeted four decades, a selection of films and newspapers was sampled from 1976 to 2006. Firstly, five top-grossing films, selected on the basis of popularity charts and youth polls, were analyzed from each of the decades under study following the sampling techniques of Shipley and Cavendar. ${ }^{9}$

6 Shaheen, K. (1999). Portrayal of Police Torture in Hindi Films \& Television Serials and its impact on Children. Retrieved from CEHAT- Centre for Enquiry Into Health and Allied Themes: www.cehat.org/publications/rd09r13.html

7 Ramasubramanian, S., \& Oliver, M. B. (2003). Portrayal of Sexual Violence in Popular Hindi Films: 1997-1999. Sex Roles , 48 (7-8), 327-336.

8 Aidman, A. (1997). Television Violence; Content, Context, and Consequences. Retrieved from Eric Digest.com: http://www.ericdigests.org/1998-2/television.htm, 1-5

$9 \quad$ Wes Shipley and Gray Cavender, 'Murder and Mayhem at the Movies', Journal of Criminal Justice and Popular Culture, vol. 9 no. 1, 2001, pp. 1-14. 
These films were examined for their portrayal of violent themes and acts. Then, following George Gerbner formula, a Violence Index was calculated to identify and compare the trends in the defined time period. ${ }^{10}$

Subsequently, focusing on crime news, four samples of one month's issues per decade of the Daily Jang, Pakistan's national Urdu daily - sometimes spreading over 20 to 30 news pages - were carefully submitted to content analysis. Eventually, the findings of the two studies were compared statistically to evaluate potential linkages.

The variable studied and coded in the sample of both movies and newspapers is percentage of the sample size having crime or violence related content represented through \%P i.e. Prevalence. It is derived by multiplying the size of the violence content calculated in terms of hours and square centimeters by the total volume of the sample.

\section{Unit of Analysis}

A basic definition of violent crime is based on offences against the person. It includes homicide (murder), aggravated assault, forcible rape, robbery, burglary, larceny-theft, auto- theft and arson which also come under the category of traditional or street crimes. The present study adopts the definition of violence used by Khan and Rashid in their study of violence on Pakistan TV. ${ }^{11}$

This definition further broadens the horizon and scope of our study and includes both overt expression of physical force of the kind noted above, and the more complex category of verbal and symbolic violence.

The latter involves "verbal threats/abuse or gestures. This might be psychologically and physically injurious to a person such as yelling, shouting, showing off weapons to threaten, mostly used as a symbol of power". ${ }^{12}$

10 George Gerbner and Larry Gross, 'Living with Television: The Violence Profile', Journal of Communication, vol. 26 no. 2, 1976, pp. 172-194.

11 Fazal Rahim Khan and I. Rashid, 'Violence in the Dramatized Entertainment of PTV', Gomal University Journal of Research, vol. 13 no. 2, 1993, pp. 205-222.

12 Nancy Signorelli, Larry Gross, and Michael Morgan, 'Violence in Television Programs: Ten Years Later', in D. Pearl, J. Lazar and L. Bouthilet (eds.), Television and Behavior: Ten Years of Scientific Progress and Implications for the 80s, Rockville, MD: National Institute of Mental Health, 1982, pp. 
The inclusion of verbal and symbolic violence widens the scope of our study in comparison to Cultural Indicator research and other such studies that are confined to acts of physical force only.

\section{Findings and Analysis:}

It is clear that there are no direct and immediate links between the number of incidents in films and news reports during the four decades. For example, the 1990s return the highest number of incidents in news reports (370) whereas the decade simultaneously shows the lowest rate of violent scenes depicted in sampled films in the same period (62).

Similarly, the decade of the 2000s exhibits the second highest number of violent incidents (360) in reported news, but second lowest number of violent scenes on film (76). Subsequently, the rest of the two decades of the 1970 s and 1980s reflects a relatively lower figure of violent crimes (76 and 275) compared to the higher number of violent scenes calculated in the top five popular Indian films (80 and 94 respectively).

Table 1: Number of Violent Incidents in Films and Newspapers (1970s2000s)

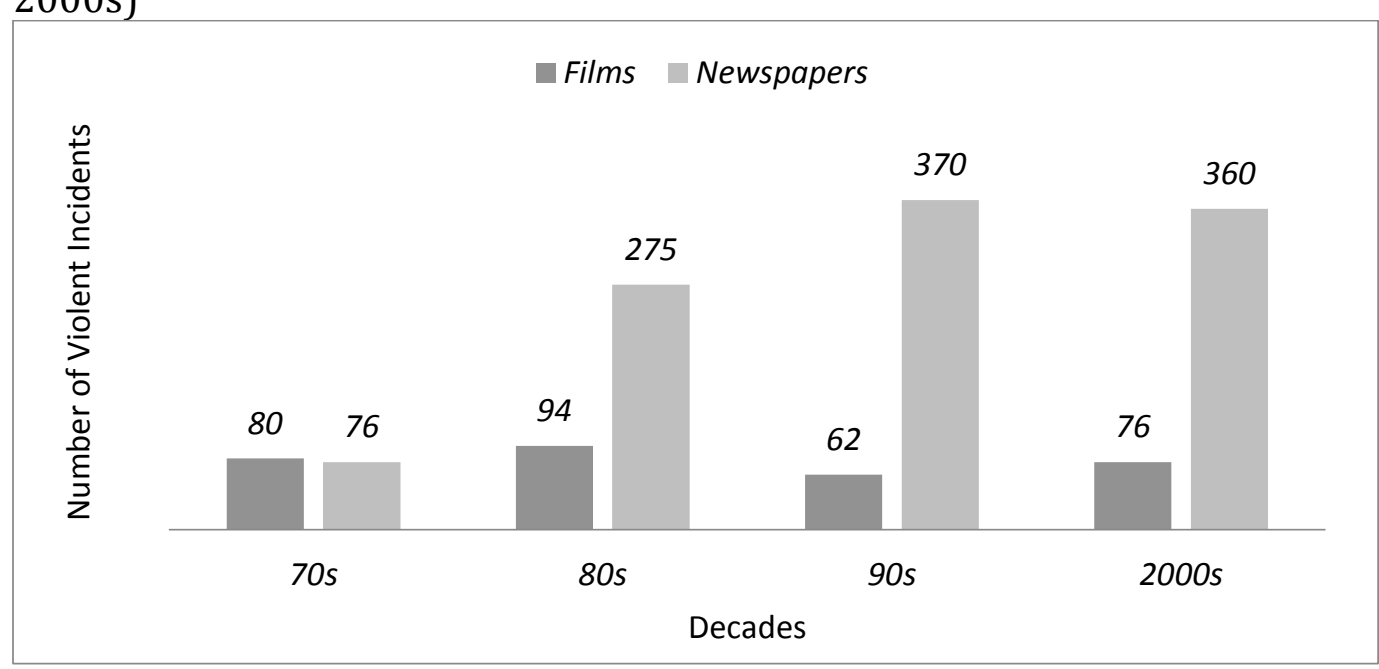

\section{Percentage or Prevalence of Violence (\%P)}

The media of film and the press are characterized by somewhat peculiar and characteristic trends as far as prevalence of violence is concerned. While the percentage of hours containing violence in films consistently decreases through four decades (from $29 \%$ in 70 s to $25 \%$ in 80 s and $16 \%$ in 90 s), it 
consistently increases in the real world of crimes news reports (from $1 \%$ to $2 \%$ between the 70 s and 80 s, and $18 \%$ in the 90 s).

The last decade proves to be an exception, with a marked decrease from $18 \%$ to $3 \%$ in newspapers, by contrast with a sharp rise from $16 \%$ to $23 \%$ in movies.

Table 2: Percentage of Violent Crimes in Films and Newspapers (1970s2000s)

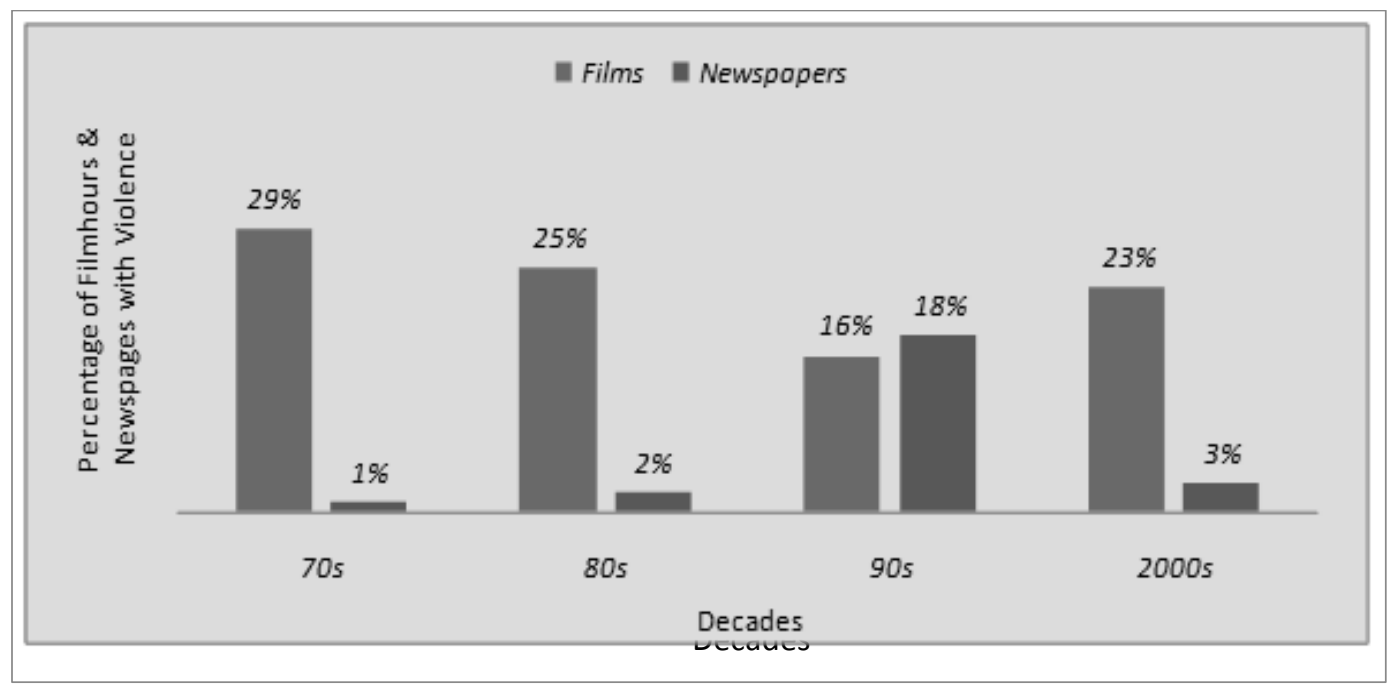

However, the findings indicate the possibility that the effects of media and film content are slow and gradual and it might take more than a decade to change the mindset of a generation - as discovered from 1960 onwards by Leonard Eron's Columbia County Longitudinal Study, focusing on 856 children living in Columbia County, New York and resulting in four waves of data across the subsequent decades. It was found that heavy viewers of onscreen violence were more likely to commit serious crimes, treat their families rather aggressively, and punish their kids seriously, than nonviewers but the media violence took more than a decade to exhibit its effects in the conduct of its viewers. ${ }^{13}$

It seems that Indian movies affect rather than reflect the social reality especially that of the neighboring country Pakistan which we attempt to

13 Leonard D. Eron, Monroe M. Lefkowitz, L. Rowell Huesmann and Leopold O. Walder, 'Does Television Violence Cause Aggression?', American Psychologist, vol. 27 no. 4, 1972, pp. 253-263 
analyze through news reports of the popular Urdu Daily which are spread over 20 to 30 pages newspaper (number of news pages are markedly increased in the last two decades). Moreover, a large number of real world crimes and violent acts remain unreported or simply sweep under the carpet, while the same acts and incidents are usually exposed and exaggerated when portrayed in Indian films which are usually two to three hours long.

\section{Discussion}

It was identified that most pictures fulfill mass audience desire for pictorial realism and provide exposure to such experiences the audience might never come across in real life. ${ }^{14}$ It is later proved that movies play a significant role to form the 'mass public' by transferring selected private perspective into broad public perspective. ${ }^{15}$

In this scenario, we might conclude that the effects of violent crimes in movies under study might not be manifested immediately in society (within the same decade) but it might contribute to the creation of mass reality and psyche which gradually affect the attitude, beliefs and actions of its regular viewers and might be traced later in life provided the person faces the similar circumstances as depicted in one recent Indian hit 'Rang De Basanti' included and analyzed in the current study.

Overall this study supports the results of around more than half of the British, American and local studies that contradict mass belief regarding the direct, necessary and sufficient detrimental effects of media violence on social crime scene. On the contrary, it strengthens the understanding that media violence, in conjunction with several other personal, psychological and socio-economic factors in the environment, might contribute to the formation of a volatile and dangerous society as argued by a range of other studies.

Even small statistical effects of media violence on aggressive behavior can have crucial social consequences, since it affects almost everyone across a large population, influences individuals gradually, and leaves lasting and subtle impressions on the unconscious mind through repetitive and

14 Vardac, A. N. (1949). Stage to Screen. Cambridge, MA: Harvard University Press

15 Gerbner, G. (2010). Proliferating Violence; Commentaries. Retrieved from www.resources metapress.com 
continual exposure over a period of time. Thus any single incident of violence can trigger pent-up emotions and result in extremely volatile reactions, as evident in various recent incidents such as the Sialkot beating to death of the Butt Brothers in 2010, the killings, stoning and burning of snatchers and burglars by mobs in Karachi, Lahore and other cities of Pakistan, and violence during the Lawyers' Campaign in Pakistan. Thus even a negligibly weak positive correlation of +0.20 between the incidences of violent crimes in movies and news reports found in the current study may be have serious social implications in the long run and inferences should be drawn with caution in the wider social perspective.

\section{Conclusion:}

The results of this study show that violence has increased both in Pakistani society and Indian films during the forty years sampled, but that the increase is curvilinear rather than linear in nature. The very fact reflects that the impact of media messages on society is rather slow, gradual and subtle, unlike the outcomes proposed by the 'hypodermic needle' or 'magic bullet theories' of yesteryear. Besides, there is a broad observation that strikingly popular Indian films (which actually fill the cinematic vacuum in absence of sufficient quality local films) play a major role in transmitting patterns of conduct and defining role models in Pakistani society. Above all the desensitization effect of excessive violence in movies on mass audience is also identified widely. 


\section{References}

Ahmed, A. S. (1992). Bombay Films: The Cinema as Metaphor for Indian Society and Politics. Modern Asian Studies, 26 (2), 289-320.

Aidman, A. (1997). Television Violence; Content, Context, and Consequences. Retrieved from Eric Digest.com: http://www.ericdigests.org/19982/television.htm, 1-5

Albert Bandura, Social Foundations of Thoughts and Actions: a Social Cognitive Theory, Englewood Cliffs, NJ: Prentice-Hall, 1986

APF Reporter 21 \# index. (2010). Gateways of India Globalization. Retrieved from aliciapatterson.org: http://aliciapatterson.org/APF2101/Wells/Wells. $\underline{\mathrm{html}}$

Fazal Rahim Khan and I. Rashid, 'Violence in the Dramatized Entertainment of PTV', Gomal University Journal of Research, vol. 13 no. 2, 1993, pp. 205222. for the 80s, Rockville, MD: National Institute of Mental Health, 1982,

George Gerbner and Larry Gross, 'Living with Television: The Violence Profile', Journal of Communication, vol. 26 no. 2, 1976, pp. 172-194.

Gerbner, G. (2010). Proliferating Violence; Commentaries. Retrieved from www.resources metapress.com

Ian Jarvie, Movies and Society, New York: Basic Books, 1970

Journal of Criminal Justice and Popular Culture, vol. 9 no. 1, 2001, pp. 1-14.

Leonard D. Eron, Monroe M. Lefkowitz, L. Rowell Huesmann and Leopold 0. Walder, 'Does Television Violence Cause Aggression?', American Psychologist, vol. 27 no. 4, 1972, pp. 253-263

Nancy Signorelli, Larry Gross, and Michael Morgan, 'Violence in Television Programs: Ten Years Later', in D. Pearl, J. Lazar and L. Bouthilet (eds.), Television and Behavior: Ten Years of Scientific Progress and Implications 
Jhss, Vol. 8, No. 1 , January to June, 2017

Ramasubramanian, S., \& Oliver, M. B. (2003). Portrayal of Sexual Violence in Popular Hindi Films: 1997-1999. Sex Roles, 48 (7-8), 327-336.

Shaheen, K. Portrayal of Police Torture in Hindi Films \& Television Serials and its impact on Children. 1999. Retrieved from CEHAT- Centre for Enquiry into Health and Allied Themes: www.cehat.org/publications/rd09r13.html

Strasburger, V. C. Media Violence. Behavioral Pediatrics-II. 66, 603-612. Indian J Pediatr. 1999

Vardac, A. N. (1949). Stage to Screen. Cambridge, MA: Harvard University Press

Wes Shipley and Gray Cavender, 'Murder and Mayhem at the Movies', 